\title{
Risk Margin Estimation through the Cost of Capital Approach: Some Conceptual Issues*
}

\author{
Alberto Floreani \\ Department of Economics and Business Administration, Faculty of Banking, Finance and Insurance \\ Sciences, Università Cattolica del Sacro Cuore, Largo Gemelli, 1, Milan, 20123 Italy. \\ E-mail: alberto.floreani@unicatt.it
}

The Solvency II directive requires that insurance liabilities are valued using a best estimate plus a risk margin. The risk margin should be estimated using the cost of capital approach, that is the cost of the solvency capital requirement - which is computed through a value at risk measure - needed to support the insurance obligation until settlement. The unitary cost of capital applied to the future capital requirement should be fixed. This paper deals with conceptual issues relating to the risk margin estimate through the cost of capital approach. It shows that the Solvency II specification of the methodology is consistent with financial economics. However, the theoretical framework required (a frictionless and normally distributed world) is too far-fetched to be acceptable. Even if these conditions were satisfied, a variable unitary cost of capital must be used.

The Geneva Papers (2011) 36, 226-253. doi:10.1057/gpp.2011.2

Keywords: cost of capital; Solvency II; risk margin; insurance contracts; fair value; accounting standards; IFRS 4

\section{Introduction}

The Solvency II European Directive (2009/138/EC) introduces a new valuation framework for technical provisions based on current exit value/fair value, that is the current amount insurance undertakings would have to pay if they were to transfer their insurance obligations immediately to another insurance undertaking (art. 76.2). More precisely, the value of insurance obligations that cannot be replicated reliably using marketed financial instruments, that is those that have some non-hedgeable risks, shall be equal to the sum total of a best estimate and a risk margin. The best estimate is the probability-weighted average of future cash flows, taking account of the time value of money, using the relevant risk-free interest rate term structure (art. 77.2) and the risk margin is an explicit and unbiased estimate of the margin that market participants require for bearing risk. ${ }^{1}$

\footnotetext{
* This research is partially supported by a grant from Carefin-Bocconi Center for Applied Research in Finance.

${ }^{1}$ In the traditional regulators' view the risk margin is also considered for policy-holder protection as an "element of prudence" (cf. Risk Margin Working Group, 2008, pp. 47-48). Conceptually, the two interpretations are broadly different, especially from shareholders' perspectives. The risk margin, being an element of prudence, delays profit realisation and this delayed result concurs with shareholders' value creation. The risk margin, being a provision for bearing risk, delays profit realisation but this delayed
} 
There are several technical approaches that can be used for risk margin estimation (cf. CEIOPS and Groupe Consultatif Actuariel Européen ${ }^{2}$ and Risk Margin Working Group $^{3}$ ). The Solvency II Directive (art. 77.5) explicitly requires the cost of capital approach, which is also the practitioners' favourite method (Chief Risk Officer Forum; ${ }^{4}$ Chief Financial Officer Forum; ${ }^{5}$ Pollard and Whitlock ${ }^{6}$ and Swiss Federal Office of Private Insurance ${ }^{7}$ ). Furthermore, the $\mathrm{IASB}^{8}$ admits that the cost of capital approach could be used in the insurance contract measurements for accounting purposes.

The driving factor behind the success of the cost of capital approach is its intuitiveness. Broadly speaking, the risks related to insurance obligations absorb capital. Therefore, the risk margin required by the market participants is the cost of the capital absorbed by insurance obligations. It is not completely clear or univocal how this simple intuition could be supported by a rational economic theory.

The practical implementation of the cost of capital approach is not so standardized (cf. Ernst \& Young). ${ }^{9}$ However, the Solvency II Directive and its Implementing Measures (cf. CEIOPS ${ }^{10}$ and Commission of the European Communities ${ }^{11}$ ) set out detailed risk margin calculation rules. A growing number of technical papers review and analyse major issues relating to the cost of capital approach (cf. Scotti; ${ }^{12}$ Ernst \& Young, ${ }^{9}$ Hitchcox et al. $;^{13}$ Risk Margin Working Group ${ }^{3,14}$ ). The main objectives of these papers are to resolve each technical issue in order to give consistency to the method and to allow its implementation.

This paper uses a different approach. It only deals with some conceptual issues rather than all the technicalities. ${ }^{15}$ The main purposes of this paper are to explain and discuss the financial economic rationale of the cost of capital approach and, more specifically, to discuss the rationale behind Solvency II cost of capital specifications. Neither purpose has been extensively addressed by scientific insurance economics literature.

result is the additional remuneration required by the shareholders for bearing risks and does not concur with shareholders' value creation. In the Solvency II framework both interpretations are considered. Hereinafter the risk margin is only considered as a provision for bearing risk.

${ }^{2}$ CEIOPS and Groupe Consultatif Actuariel Européen (2006).

${ }^{3}$ Risk Margin Working Group (2007).

${ }^{4}$ Chief Risk Officer Forum (2006 and 2008).

${ }^{5}$ Chief Financial Officer Forum (2009).

${ }^{6}$ Pollard and Whitlock (2006).

${ }^{7}$ Swiss Federal Office of Private Insurance (2004).

${ }^{8}$ cf. IASB (2010).

${ }^{9}$ Ernst \& Young (2007).

${ }^{10}$ CEIOPS (2009).

${ }^{11}$ Commission of the European Communities (2010).

12 Scotti (2005).

${ }^{13}$ Hitchcox et al. (2007).

14 Risk Margin Working Group (2007 and 2008).

${ }^{15}$ Due to the specific scope of the paper at hand, a large number of relevant issues concerning insurance contract valuation are not addressed. These include, among others: expected cash flows and risk-free rate estimation issues, such as those concerning liquidity risk premium, given that liability cash flows are less liquid than risk-free assets (cf. Risk Margin Working Group, 2008, section 5.3); the unit of account issues (cf. IASB, 2007, §§183-202) and participating contract issues (cf. IASB, 2007, Chapter 6). 
With reference to the first objective, the paper demonstrates that the cost of capital approach has a strong rationale. In particular, the risk margin could be related to unhedgeable systematic risk, other unhedgeable priced risks, frictional costs relating to priced risks or expected frictional costs that are not considered in the cash flow estimate, even if the latter is not a cost of capital in the financial economic sense. The important role of systematic risks - often neglected in Solvency II - in the risk margin estimation is also discussed hereinafter.

With reference to the second objective, this paper demonstrates the conditions under which the Solvency II cost of capital specification is rational. These conditions seem to be far-fetched. In addition, even if these conditions were satisfied, a variable cost of capital rate should be set. In order to render the Solvency II cost of capital specification more in line with financial economic rationale, at least a different unitary cost of capital across various lines of business is required.

This paper adopts the classic financial economic valuation approach, which uses, as a starting point, a normally or lognormally frictionless distributed world to price random future cash flows. Under this framework, three theoretically equivalent pricing methods could be used: ${ }^{16}$ the certainty equivalent approach (modify the cash flow by calculating the certainty equivalent and then discounting it with the risk-free rate); the risk premium approach (adjust the discount factor by adding a risk premium, e.g. using Capital Asset Pricing Model (CAPM)); the risk-neutral pricing approach (modify the probabilities to risk-neutral probabilities, e.g. using Option Pricing). In insurance economics literature the financial economic valuation approach has been widely used. Among others, Doherty and Garven, ${ }^{17}$ use this approach for insurance price regulation, Phillips et al., ${ }^{18}$ for multiple-line-insurance company valuations and Sherris, ${ }^{19}$ for capital allocation (cf. also Cummins ${ }^{20}$ and Butsic ${ }^{21}$ ). This paper first applies this framework to the technical provision valuation, in order to analyse and discuss the risk margin estimation, through the cost of capital approach, which could be interpreted as a certainty equivalent pricing method (cf. Eqs. (3), (18) and (19)).

Even if theoretical, this paper has immediate practical implications for solvency and accounting standard-setters and contributes to the current debate on fair value measurement (cf., among others, Flamee ${ }^{22}$ and Duverne and Le Douit; ${ }^{23}$ Klumpes et $a .^{24}$ ), solvency regulation (cf., among others, Doff ${ }^{25}$ and Holzmüller ${ }^{26}$ ) and insurance contract accounting (cf., among others, Duverne and Le Douit ${ }^{27}$ ).

16 cf. Babbel and Merrill (1998).

17 Doherty and Garven (1986).

${ }^{18}$ Phillips et al. (1998).

${ }^{19}$ Sherris (2006).

${ }^{20}$ Cummins (1991).

${ }^{21}$ Butsic (1994).

${ }^{22}$ Flamee (2008).

${ }^{23}$ Duverne and Le Douit (2009).

${ }^{24}$ Klumpes et al. (2009).

25 Doff (2008).

${ }^{26}$ Holzmüller (2009).

${ }^{27}$ Duverne and Le Douit (2008). 
This paper is organized as follows. In the next section the risk margin algebra is introduced using a single period model. This leads to three possible specifications: an indirect cost-of-capital approach; a direct cost-of-capital approach; and a frictional cost approach. The Solvency II cost of capital approach is also introduced and linked to the three risk margin specifications. In the following section, the financial economics rationale of the risk margin estimation is introduced and discussed. The financial economics rationale for the Solvency II cost of capital approach is discussed in the subsequent section. The last section concludes the matter.

\section{The cost of capital approach}

The Solvency II value of technical provision on an insurance contract portfolio (TP) is equal to the present value of future cash outflows plus the risk margin computed using the cost of capital approach. In equation:

$$
T P=\sum_{t=1}^{T} \frac{E\left(\boldsymbol{F}_{t}\right)}{\left(1+i_{t}\right)^{t}}+\sum_{t=1}^{T} \frac{c_{t} \times C_{t}}{\left(1+i_{t}\right)^{t}}
$$

where $\boldsymbol{F}_{t}$ is the random net cash outflow of period $t, E($.$) is the expected value$ operator, $i_{t}$ is the appropriate discounting rate, ${ }^{28} c_{t}$ is the unitary cost of capital for period $t$ and $C_{t}$ is the capital in the period.

The main issues in the cost of capital approach relate to the definition and calculation of the capital and the unitary cost of capital. In the Solvency II methodology the capital base is the Solvency Capital Requirement (SCR) regarding non-hedgeable risks (essentially operational, underwriting and unavoidable market risks relating to insurance obligations) and the cost of capital rate shall be equal to the additional rate, above the relevant risk-free interest rate, that an insurance undertaking holding an amount of eligible own funds equal to the Solvency Capital Requirement would incur to hold those funds (art. 77.5). Furthermore, the cost of capital rate shall be the same for all insurance and reinsurance undertakings and shall be reviewed periodically. The CEIOPS propose a fixed unitary cost of capital irrespective of the lines of business involved in the risk margin estimation ( 6 per cent according to CEIOPS ${ }^{10}$ and Commission of the European Communities $\left.{ }^{11}\right)$.

This paper deals with conceptual issues relating to the fair valuation of insurance contracts, rather than technical issues. Therefore, it is useful to employ a single-period model, that is the insurance company has only got a portfolio of insurance liabilities that determines a single stochastic net cash outflow at the end of the period (time 1) equal to $\boldsymbol{L}_{\mathbf{1}}$. In order to focus solely on non-hedgeable risks in insurance contracts, it should be assumed that all hedgeable risks in assets and liabilities are effectively hedged and that all asset risks are hedgeable. In this situation the asset cash inflow at

\footnotetext{
${ }^{28}$ In the Solvency II directive the expected cash outflows are discounted using the "relevant risk-free interest rate term structure" (art. 77). The possible inclusion of the liquidity premium in the discount rate, as suggested in Commission of the European Communities, 2010, is not addressed in this paper.
} 
Table 1 Simplified insurance company balance sheet

\begin{tabular}{ll}
\hline Assets & Liabilities \\
\hline$A-$ Fair value representation & \\
$A_{0}=V\left(A_{1}\right)$ & $\begin{array}{l}P_{0}=V\left(P_{1}\right)=V\left(L_{1}\right)-V\left(M A X\left[L_{1}-A_{1} ; 0\right]\right) \\
E_{0}=A_{0}-P_{0}=V\left(M A X\left[A_{1}-L_{1} ; 0\right]\right)\end{array}$ \\
\hline$B-$ Fulfilment value representation & \\
$A_{0}=V\left(A_{1}\right)$ & $L_{0}=V\left(L_{1}\right)$ \\
& $S_{0}=A_{0}-L_{0}=V\left(A_{1}\right)-V\left(L_{1}\right)$ \\
\hline
\end{tabular}

the end of the period $\left(A_{1}\right)$ is non-stochastic. The difference, if positive, between the net cash inflow and outflow is given to the shareholders. In the case that the contractual outflow is greater than the inflow $A_{1}$ the shareholders use their limited liability, the company is bankrupted and the policy-holders become the residual claimants and receive all assets $A_{1}$.

Therefore, the shareholders' and policy-holders' payoffs at time 1 are:

$$
\begin{gathered}
\boldsymbol{E}_{\boldsymbol{l}}=\operatorname{MAX}\left[A_{1}-\boldsymbol{L}_{\boldsymbol{l}} ; 0\right] \\
\boldsymbol{P}_{\boldsymbol{1}}=A_{1}-M A X\left[A_{1}-\boldsymbol{L}_{\boldsymbol{l}} ; 0\right]=\boldsymbol{L}_{\boldsymbol{l}}-\operatorname{MAX}\left[\boldsymbol{L}_{\boldsymbol{l}}-A_{1} ; 0\right]
\end{gathered}
$$

Consequently, the insurance company balance sheet at time 0 could be represented in Table 1 , where $V($.$) is the value operator.$

The fair value representation 1-A takes the shareholders' limited liability into account and so liabilities and equity are consistently priced with the insurance firm's default scenarios. Table 1-B only considers the contractual obligation $\boldsymbol{L}_{\mathbf{1}}$ without the possibility of default. This representation is consistent with the Solvency II framework that requires a fair valuation of all assets and liabilities, except for the insurance firm's own credit risk (hereinafter this value is referred to as current fulfilment value). In order to avoid confusion in the terminology $\boldsymbol{L}_{\mathbf{1}}, \boldsymbol{P}_{\mathbf{1}}, \boldsymbol{S}_{\mathbf{1}}$ and $\boldsymbol{E}_{\mathbf{1}}$ represent, respectively, contractual obligations, insurance liabilities, net assets and equity. The difference $\boldsymbol{L}_{\mathbf{1}}-\boldsymbol{P}_{\mathbf{1}}$ is equal to:

$$
\boldsymbol{C}_{\boldsymbol{1}}=\boldsymbol{L}_{\boldsymbol{1}}-\boldsymbol{P}_{\boldsymbol{1}}=\boldsymbol{E}_{\boldsymbol{1}}-\boldsymbol{S}_{\boldsymbol{1}}=\operatorname{MAX}\left[\boldsymbol{L}_{\boldsymbol{1}}-A_{1} ; 0\right]
$$

and represents the payoff of the default option. This representation is well known in the literature, even if compared to the classical financial economics representation introduced by Merton $^{29}$ and Black and Scholes ${ }^{30,31}$, the default option is a call on

\footnotetext{
${ }^{29}$ Merton (1974).

${ }^{30}$ Black and Scholes (1973).

${ }^{31}$ cf. also Cummins et al. (2000); Babbel et al. (2002).
} 
$\boldsymbol{L}_{\mathbf{1}}$ (which is stochastic, due to insurance risks) and not a put on $A_{1}$ (which is nonstochastic, since hedgeable risks are effectively hedged). ${ }^{32}$

\section{The risk margin algebra}

In the case of a single cash outflow the value of technical provision on an insurance contract portfolio is (cf. Eq. (1)):

$$
T P=L_{0}=\frac{E\left(\boldsymbol{L}_{\boldsymbol{I}}\right)}{\left(1+r_{f}\right)}+\frac{c \times C}{\left(1+r_{f}\right)}=\frac{E\left(\boldsymbol{L}_{\boldsymbol{l}}\right)+c \times C}{\left(1+r_{f}\right)}
$$

where $c$ is the cost of capital, $C$ is the capital base and $r_{f}$ is the risk-free rate. The last part of Eq. (3) suggests that the pricing approach implicit in the risk margin calculation is a certainty equivalent approach. Therefore, the product between $c$ and $C$ could be interpreted as the certainty equivalent risk adjustment.

Let us define the expected rate of return on contractual insurance obligations as:

$$
r_{L} \equiv \frac{E\left(\boldsymbol{L}_{1}\right)}{L_{0}}-1
$$

The rate of return on assets is the risk-free rate, $r_{f}$, since $A_{1}$ is non-stochastic.

Similarly, the expected rate of return on the difference $A_{1}-\boldsymbol{L}_{\mathbf{1}}$ (the net asset, $\boldsymbol{S}_{\mathbf{1}}$ ) is defined as:

$$
r_{S} \equiv \frac{E\left(\boldsymbol{S}_{1}\right)}{S_{0}}-1
$$

With simple algebra, the expected net asset rate of return can be computed from the return on assets and the return on contractual obligations. More precisely, the rate of return on the net asset is:

$$
r_{S}=r_{f}+\left(r_{f}-r_{L}\right) \times \frac{L_{0}}{S_{0}}
$$

The fair value of contractual liabilities (i.e. the fulfilment value) is computable using different approaches. Considering Eqs. (4)-(6), simple algebra is enough to obtain a specification of the risk margin parameter $c$ and $C$ in $\mathrm{Eq}$ (3). More specifically, two different and theoretically equivalent cost of capital specifications could be obtained.

${ }^{32}$ If $\mathrm{A}_{1}$ were also stochastic, that is asset risks were not completely hedgeable, there would be a technically complex exchange option (cf. Margrabe, 1978; Cummins, 1991) without any additional conceptual issues. 
The first specification, hereinafter referred to as the direct cost of capital approach, may be directly obtained from Eq. (4): ${ }^{33}$

$$
\begin{aligned}
L_{0} & =\frac{E\left(\boldsymbol{L}_{\boldsymbol{1}}\right)}{\left(1+r_{f}\right)}+\frac{E\left(\boldsymbol{L}_{\boldsymbol{1}}\right) \times\left(r_{f}-r_{L}\right)}{\left(1+r_{f}\right) \times\left(1+r_{L}\right)} \\
& =B E\left(\boldsymbol{L}_{\boldsymbol{1}}\right)+R M\left(\boldsymbol{L}_{\boldsymbol{1}}\right)
\end{aligned}
$$

According to Eq. (7) the value of contractual liabilities is equal to the expected value of contractual liabilities discounted at the risk-free rate (i.e. the best estimate, $B E\left(\boldsymbol{L}_{\mathbf{1}}\right)$ ), plus a risk margin $\left(R M\left(\boldsymbol{L}_{\mathbf{1}}\right)\right)$ that may be computed by using the contractual obligation characteristics. In particular, it could be computed by using the contractual obligations' expected net cash outflows and the spread between the riskless rate and the rate of expected return on the contractual obligations. In order to obtain a positive risk margin, the expected rate of return on contractual obligations should be less than the riskless rate. The positive difference between $r_{f}$ and $r_{L}$ has a simple and intuitive explanation. Every insurance contract offers protection against some kind of risk. In the primary markets the policy-holder is willing to pay more than the present value of expected future contractual cash inflows to acquire protection against a risk (the certainty equivalent for the policy-holder is greater than the insurance contract expected cash flows). Similarly, in the secondary market the underwriting company is willing to pay more than the best estimate to protect itself from the risks insured, that is to negotiate the contractual obligations.

The second specification, hereinafter referred to as the indirect cost of capital approach, may be obtained applying Eqs. (6)-(7):

$$
L_{0}=\frac{E\left(\boldsymbol{L}_{\boldsymbol{l}}\right)}{\left(1+r_{f}\right)}+\frac{S_{0} \times\left(r_{S}-r_{f}\right)}{\left(1+r_{f}\right)}
$$

According to Eq. (8), the value of contractual liabilities is equal to the expected value of contractual liabilities discounted at the risk-free rate plus a risk margin that may be indirectly computed by using the net asset characteristics. More specifically, the risk margin in (8) is computed as the present value of the product between the net assets and the risk premium on net assets, that is the net asset cost of capital in excess to the risk-free rate.

Summarizing the technical provision risk adjustment could be computed directly using the liability expected rate of return or indirectly using the expected rate of return

${ }^{33}$ From Eq. [4], $L_{0}=E\left(L_{1}\right) /\left(1+r_{L}\right)$, with $r_{L}=r_{f}+\left(r_{L}-r_{f}\right)$, i.e. the sum between the risk-free rate $\mathrm{r}_{\mathrm{f}}$ and the risk premium $\left(r_{L}-r_{f}\right)$. Considering the following identity:

$$
\frac{X}{1+a+b}=\frac{X}{1+a}+\frac{X \times-b}{(1+a+b) \times(1+a)(*)}
$$

which is true for every real number $X$, a (with $a \neq-1$ ) and b (with $1+a+b \neq 0$ ), Eq. [7] is obtained with $a=r_{f}$ and $b=\left(r_{L}-r_{f}\right)$. Eqs. [8]-[10] are also all based on Eq. [*]. 
on equity. The risk margin in Eq. (8) seems to be unaffected by the characteristics of the contractual liability. This critical point is discussed later. However, it should be underlined that the direct and indirect cost of capital approaches are two alternative and theoretically equivalent ways to compute the same amount.

The same algebra may be applied to the insurance liabilities and equity (the fair value representation in Table 1-A), in order to obtain:

$$
P_{0}=\frac{E\left(\mathbf{P}_{\mathbf{1}}\right)}{\left(1+r_{f}\right)}+\frac{E\left(\mathbf{P}_{\mathbf{1}}\right) \times\left(r_{f}-r_{P}\right)}{\left(1+r_{P}\right) \times\left(1+r_{f}\right)}
$$

and

$$
P_{0}=\frac{E\left(\mathbf{P}_{\mathbf{1}}\right)}{\left(1+r_{f}\right)}+\frac{E_{0} \times\left(r_{e}-r_{f}\right)}{\left(1+r_{f}\right)}
$$

Actually, due to the fact that $\boldsymbol{P}_{\mathbf{1}}$ is a contingent claim on $\boldsymbol{L}_{\mathbf{1}}$, the $P_{0}$ estimation could be made easier throughout the $L_{0}$ valuation and afterwards applying an option pricing approach, as in the numerical examples hereinafter.

In addition to the direct and indirect cost of capital approaches, the risk margin estimate could also be based on a frictional cost approach. According to this approach, the cash outflows $\boldsymbol{L}_{\mathbf{1}}$ do not consider some additional costs related to the insurance contracts portfolio (the frictional costs). The risk margin is the value of these frictional costs. In its simpler specification, referred hereinafter as the pure frictional cost approach, only frictional costs are relevant in the risk margin estimation and no risk premium on frictional costs is required by market participants. Therefore, the pure frictional cost risk margin is the present value of the expected frictional costs, that is:

$$
L_{0}=\frac{E\left(\boldsymbol{L}_{\boldsymbol{1}}\right)}{\left(1+r_{f}\right)}+\frac{E\left(\boldsymbol{F} \boldsymbol{C}_{\boldsymbol{1}}\right)}{\left(1+r_{f}\right)}
$$

where $\boldsymbol{F C}_{\mathbf{1}}$ are the frictional costs relating to the insurance contracts portfolio. The pure frictional cost approach is not a valuation approach in the financial economics sense, that is there is no risk adjustment and all expected cash flows are discounted at the risk-free rate. However, expected frictional costs influence the value of insurance liabilities. Therefore, the expected frictional costs determined by the insurance liabilities should be considered (improperly) in the risk margin if not yet (correctly) considered in the best estimate. A more comprehensive specification of the frictional cost approach should consider the interaction with the cost of capital approach. This leads to:

$$
\begin{aligned}
L_{0}= & \frac{E\left(\boldsymbol{L}_{\boldsymbol{1}}\right)}{\left(1+r_{f}\right)}+\frac{E\left(\boldsymbol{F} \boldsymbol{C}_{\boldsymbol{1}}\right)}{\left(1+r_{f}\right)}+\frac{E\left(\boldsymbol{L}_{\boldsymbol{1}}\right) \times\left(r_{f}-r_{L}\right)}{\left(1+r_{f}\right) \times\left(1+r_{L}\right)} \\
& +\frac{E\left(\boldsymbol{F} \boldsymbol{C}_{\boldsymbol{1}}\right) \times\left(r_{f}-r_{F C}\right)}{\left(1+r_{f}\right) \times\left(1+r_{F C}\right)}
\end{aligned}
$$


where the last addendum is the risk adjustment due to frictional costs (cf. discussion in the section "The effect of frictional costs on the risk margin"). In the section "The consistency of the frictional cost approach" in order to address the consistency of the Solvency II cost of capital specification, the costs of distress are considered, that is frictional costs are supposed to be proportional to the seriousness of the distress. However, it should be underlined that the frictional cost approach (the second addendum in the second part of Eq. (12)) and the cost of capital approach (the third addendum) are conceptually different - and possibly interdependent as the fourth addendum suggests. As a matter of fact, in the Market Consistent Embedded Value Principles (cf. Chief Financial Officer Forum ${ }^{5}$ ) the "cost of residual non hedgeable risk" and the "frictional costs of required capital" are two different and autonomously estimated embedded value components.

\section{The Solvency II cost of capital approach}

In the case of a single cash outflow the Solvency II value of technical provision on an insurance contract portfolio is (cf. Eq. (1)):

$$
\begin{aligned}
T P=L_{0} & =\frac{E\left(\boldsymbol{L}_{\boldsymbol{1}}\right)}{\left(1+r_{f}\right)}+\frac{c \times C\left(\boldsymbol{L}_{\boldsymbol{1}}\right)}{\left(1+r_{f}\right)} \\
& =\frac{E\left(\boldsymbol{L}_{\boldsymbol{1}}\right)}{\left(1+r_{f}\right)}+\frac{c \times S C R\left(\boldsymbol{L}_{\boldsymbol{1}}\right)}{\left(1+r_{f}\right)}
\end{aligned}
$$

where $\operatorname{SCR}\left(\boldsymbol{L}_{\mathbf{1}}\right)$ is the SCR required to support non-hedgeable risks in $\boldsymbol{L}_{\mathbf{1}}, c$ is the fixed unitary cost of capital ( 6 per cent according to Commission of the European Communities ${ }^{11}$ ) and $r_{f}$ is the risk-free rate.

The Solvency II specification in (13) has both a direct and indirect cost of capital interpretation. Moreover, a pure frictional costs interpretation is possible.

The indirect cost of capital interpretation is simpler and more intuitive. The risk margin is calculated as the cost of capital of a hypothetical insurance company that acquires the evaluating insurance portfolio. This reference entity needs to have equity funds exactly equal to the SCR that are necessary to support the acquired obligations (cf. CEIOPS ${ }^{34}$, proposal 3). The cost of capital approach is applied to the reference entity SCR with a fixed unitary cost of capital.

The direct cost of capital interpretation requires more complex reasoning. According to the Solvency II directive, the SCR is based on a Value at Risk approach at a 99.5 per cent confidence level and over a one-year time horizon. More precisely, the SCR is the capital in excess of the liability value that the insurance company should have at the evaluation date in order to be solvent with 99.5 per cent probability at the end of the period. Therefore, the necessary assets to preclude insolvency at time 1 are:

$$
A_{1}=p_{99.5 \%}\left(\boldsymbol{L}_{\boldsymbol{l}}\right)=\operatorname{VaR}_{99.5 \%}\left(\boldsymbol{L}_{\boldsymbol{l}}\right)+E\left(\boldsymbol{L}_{\boldsymbol{l}}\right)
$$

\footnotetext{
${ }^{34}$ CEIOPS (2008).
} 
where $p_{99.5 \%}\left(\boldsymbol{L}_{\mathbf{1}}\right)$ is the 99.5 per cent quantile of the cash outflow distribution and $\operatorname{VaR}_{99.5 \%}\left(\boldsymbol{L}_{\mathbf{1}}\right)$ is equal to the distance between the expected cash outflow and the 99.5 per cent quantile, ${ }^{35}$ that is $\operatorname{VaR}_{99.5 \%}\left(\boldsymbol{L}_{\mathbf{1}}\right)=p_{99.5 \%}\left(\boldsymbol{L}_{\mathbf{1}}\right)-E\left(\boldsymbol{L}_{\mathbf{1}}\right)$. The SCR required at time 0 is: ${ }^{36}$

$$
\begin{aligned}
\operatorname{SCR}\left(\boldsymbol{L}_{\boldsymbol{I}}\right) & =\frac{A_{1}}{\left(1+r_{f}\right)}-L_{0}=\frac{\operatorname{VaR}_{99.5 \%}\left(\boldsymbol{L}_{\boldsymbol{1}}\right)+E\left(\boldsymbol{L}_{\boldsymbol{1}}\right)}{\left(1+r_{f}\right)}-L_{0} \\
& =\frac{\operatorname{VaR}_{99.5 \%}\left(\boldsymbol{L}_{\boldsymbol{1}}\right)}{\left(1+r_{f}\right)}-\left[L_{0}-\frac{E\left(\boldsymbol{L}_{\boldsymbol{1}}\right)}{\left(1+r_{f}\right)}\right] \\
& =\frac{\operatorname{VaR}_{99.5 \%}\left(\boldsymbol{L}_{\boldsymbol{1}}\right)}{\left(1+r_{f}\right)}-R M\left(\boldsymbol{L}_{\boldsymbol{l}}\right)
\end{aligned}
$$

where $R M\left(\boldsymbol{L}_{\mathbf{1}}\right)$ is the risk margin (cf. Eq. (13)).

If the spread $\left(r_{f}-r_{L}\right)$, is proportional to the ratio between a generic risk measure $R$ on $\boldsymbol{L}_{\mathbf{1}}$ and the current value $L_{0}$, that is

$$
\left(r_{f}-r_{L}\right)=\frac{k \times R\left(\boldsymbol{L}_{\boldsymbol{1}}\right)}{L_{0}}
$$

then Eq. (7) becomes:

$$
\begin{aligned}
L_{0} & =\frac{E\left(\boldsymbol{L}_{\boldsymbol{1}}\right)}{\left(1+r_{f}\right)}+\frac{L_{0}}{\left(1+r_{f}\right)} \times \frac{k \times R\left(\boldsymbol{L}_{\boldsymbol{1}}\right)}{L_{0}} \\
& =\frac{E\left(\boldsymbol{L}_{\boldsymbol{1}}\right)}{\left(1+r_{f}\right)}+\frac{k \times R\left(\boldsymbol{L}_{\boldsymbol{1}}\right)}{\left(1+r_{f}\right)}
\end{aligned}
$$

If the relevant risk measure $R($.$) is the S C R\left(\boldsymbol{L}_{\mathbf{1}}\right)$ or the $\operatorname{VaR} R_{99.5 \%}\left(\boldsymbol{L}_{\mathbf{1}}\right)$ risk measure, the Solvency II cost of capital Eq. (13) is obtained and the risk margin is equal to:

$$
R M\left(\boldsymbol{L}_{\boldsymbol{1}}\right)=\frac{k_{S} \times \operatorname{SCR}\left(\boldsymbol{L}_{\boldsymbol{1}}\right)}{\left(1+r_{f}\right)}=\frac{k_{v} \times \operatorname{Va} R_{99.5 \%}\left(\boldsymbol{L}_{\boldsymbol{1}}\right)}{\left(1+r_{f}\right)}
$$

where $k_{s}=\left(1+r_{f}\right) \times k_{v} /\left(1-k_{v}\right)$. Again, in the Solvency II specification $k_{s}=6$ per cent.

Lastly, further to the pure frictional cost approach, the Solvency II specification could be obtained if the frictional costs were proportional to the SCR or the VaR measures. In this situation the $k_{s}$ or $k_{v}$ parameters in (15) could be interpreted as the cost of frictions for a unit of SCR or VaR.

${ }^{35}$ In the Solvency II framework the VaR is usually defined as a "maximum potential loss", that is as a quantile. For convenience, throughout this paper all risk measures are defined as variability measures. Therefore, the VaR is defined as the difference between the maximum potential loss and the expected loss, that is the unexpected potential loss. A similar definition is used for the Tail-VaR in the section "The consistency of the frictional cost approach".

${ }^{36}$ It should be highlighted that Solvency II prescribes that the SCR used in the risk margin computation does not consider the insurance companies' hedgeable risks. 


\section{The theoretical foundation of the cost of capital approach}

The main objective of this paper is to discuss the theoretical consistency of the Solvency II cost of capital approach or, more specifically, if one or more of the interpretations discussed in the previous section are consistent with financial economics. In order to reach this objective a theoretical foundation of the cost of capital approach is useful. Hereinafter, it is argued that the risk margin should consider:

- non-hedgeable systematic risks;

- other non-hedgeable priced risks;

- the effects of the frictional costs relating to priced risks;

- the expected value of frictional costs, if not yet considered in the best estimate.

Preliminarily, it is important to highlight that under both the direct and indirect cost of capital approaches the risk margin depends only on priced risk sources, that is risk factors that affect the expected rate of return on contractual obligations $\left(r_{L}\right)$ or on net assets $\left(r_{S}\right)$. More specifically, if no priced risk source exists, the risk margin is zero. Therefore, the main step for the theoretical foundation of the cost of capital approach is to detect the priced risk sources.

\section{The perfect market case}

As a starting point it could be useful to consider a perfect market model: insurance risks are supposed to be tradable and hedgeable in a perfect and complete capital market; the fair value of contractual obligations and other stochastic payoffs are directly observable in the markets.

If $\boldsymbol{L}_{\mathbf{1}}$ is lognormally distributed, the classic Black and Scholes formula could be applied to price insurance equities and liabilities. This is useful for the numerical examples hereinafter. More important for the discussion is the fact that in the perfect market case the CAPM could also be assumed to hold. More specifically, with a lognormally distributed $\boldsymbol{L}_{\mathbf{1}}$, the Merton ${ }^{37}$ continuous CAPM applies.

Alternatively, it could also be useful to consider a frictionless model based on the less frequently used normal distribution of $\boldsymbol{L}_{\mathbf{1}}$. In this situation the single period Black and Scholes formula is applied to evaluate insurance liabilities and equity (cf. Brennan, ${ }^{38}$ formula 39) and the spreads $\left(r_{f}-r_{L}\right)$ and $\left(r_{S^{-}} r_{f}\right)$ could be computed throughout the traditional CAPM, that is:

$$
\begin{aligned}
& \left(r_{f}-r_{L}\right)=\beta_{L} \times\left(\bar{r}_{m}-r_{f}\right) \\
& \left(r_{s}-r_{f}\right)=\beta_{S} \times\left(\bar{r}_{m}-r_{f}\right)
\end{aligned}
$$

where $\beta_{L}$ and $\beta_{S}$ are respectively the contractual liability beta and the net assets beta, that is the systematic risk measure, and $\bar{r}_{m}$ is the expected return on the market

\footnotetext{
${ }^{37}$ Merton (1973).

${ }^{38}$ Brennan (1979).
} 
portfolio. Therefore, under the CAPM, the contractual liability risk margin is only affected by systematic risk. For instance, Eq. (7) becomes:

$$
\begin{aligned}
L_{0} & =\frac{E\left(\boldsymbol{L}_{\boldsymbol{l}}\right)-L_{0} \times \beta_{L} \times\left(\bar{r}_{m}-r_{f}\right)}{\left(1+r_{f}\right)} \\
& =\frac{E\left(\boldsymbol{L}_{\boldsymbol{l}}\right)-L_{0} \times \beta_{L} \times \sigma^{\prime}\left(\boldsymbol{r}_{\boldsymbol{m}}\right) \times\left(\bar{r}_{m}-r_{f}\right) / \sigma^{\prime}\left(\boldsymbol{r}_{\boldsymbol{m}}\right)}{\left(1+r_{f}\right)} \\
& =\frac{E\left(\boldsymbol{L}_{\boldsymbol{1}}\right)-L_{0} \times \beta_{L} \times \sigma^{\prime}\left(\boldsymbol{r}_{\boldsymbol{m}}\right) \times \tau}{\left(1+r_{f}\right)}
\end{aligned}
$$

where $\sigma^{\prime}\left(\boldsymbol{r}_{\boldsymbol{m}}\right)$ is the standard deviation of market portfolio return and $\tau=\left(\bar{r}_{m}-r_{f}\right) / \sigma^{\prime}\left(\boldsymbol{r}_{\boldsymbol{m}}\right)$ is the market price of risk. The latter part of equation [18] is essentially the well-known certainty-equivalent form of the CAPM (cf. Brealy and Myers ${ }^{39}$, Chapter 9). Therefore, under the CAPM, the risk margin could be viewed as the product between the market price of risk $\tau$ and a measure of the contractual liability systematic risk, that is:

$$
\begin{aligned}
R M\left(\boldsymbol{L}_{\boldsymbol{I}}\right) & =\frac{-L_{0} \times \beta_{L} \times\left(\bar{r}_{m}-r_{f}\right)}{\left(1+r_{f}\right)} \\
& =\frac{\left[\left(\bar{r}_{m}-r_{f}\right) / \sigma^{\prime}\left(\boldsymbol{r}_{\boldsymbol{m}}\right)\right] \times\left[-L_{0} \times \beta_{L} \times \sigma^{\prime}\left(\boldsymbol{r}_{\boldsymbol{m}}\right)\right]}{\left(1+r_{f}\right)} \\
& =\frac{\tau \times R\left(\boldsymbol{L}_{\boldsymbol{I}}\right)}{\left(1+r_{f}\right)}
\end{aligned}
$$

where $R\left(\boldsymbol{L}_{\mathbf{1}}\right)=-L_{0} \times \beta_{L} \times \sigma^{\prime}\left(\boldsymbol{r}_{\boldsymbol{m}}\right)$. The relationship between the Solvency II risk margin in (15) and the risk adjustment based on the certainty-equivalent form of the CAPM in (19) will be addressed hereinafter.

\section{The no-frictions hypothesis and the role of systematic risk}

In a frictionless market, only systematic risks affect the risk margin because systematic risk is the sole-priced risk (cf. Eqs. (16)-(19)). However, if the risk margin only considers non-hedgeable risks, in a perfect and complete market, the risk margin should be equal to zero, essentially because all risks are hedgeable. In real markets the situation could be slightly different. In particular, not all systematic risks are hedgeable, as marketable securities only represent a part of the market portfolio, that is the portfolio of all endowments in the entire world. ${ }^{40}$ In particular, insurance contracts are non-tradable and it is not so straightforward to relate the systematic risk of the contracts to marketable securities or hedging instruments. In life insurance, the systematic component of lapse, that is the relationship between lapse, interest rates

\footnotetext{
${ }^{39}$ Brealy and Myers (2003).

${ }^{40} \mathrm{cf}$. Athanasoulis and Shiller (2000).
} 
and/or the GNP growth, could be significant. The interest rate risk in lapse can be at least partially hedged, but the GNP growth risks are not likely to be so easily hedged. In non-life insurance the relationship between contractual cash outflows, GNP growth and the inflation rate could also be relevant. In order to correctly price insurance contracts, a deep analysis of the systematic non-hedgeable components should be performed since theoretical and practical reasoning suggest that the systematic components should be adequately priced.

Therefore, the risk margin calculation should consider non-hedgeable systematic risks. The relevance of systematic risk in insurance pricing is traditionally undermined, due to the fact that insurance economics usually assumes that all sources of systematic risk are marketable and hedgeable (for instance, Santomero and Babbel ${ }^{41}$ treat the terms "systematic risk" and "market risk" as synonyms).

\section{Priced risks}

The risk margin does not only depend on unhedgeable systematic risk but also on other frictions. Frictions could affect the value of insurance contracts through a priced risk source, that is a risk or market friction that influences the expected rate of liability return required by the market and a non-priced risk source, that is a risk or a market friction that has no influence on the expected rate of liability return.

The priced risk source could derive from a non-hedgeable systematic risk or a non-systematic risk that is nevertheless priced by market participants. For example, there is some theoretical and empirical evidence ${ }^{42}$ that catastrophe risks are priced by the reinsurance market.

The existence of more than one priced risk source implies that more than one risk measure should be necessary to correctly estimate the risk margin. For instance, the liability beta could be used to compute the systematic component of the risk margin, while a downside risk measure could be used to price the catastrophe risk. Other priced risk sources might be priced through other risk measures. The possible existence of more than one priced risk source is a critical point in the application of the cost of capital approach proposed by the Solvency II directive.

\section{The effect of frictional costs on the risk margin}

In order to ensure that the risk margin is correctly estimated, it is important to consider not only priced risks but frictional costs, that is the liability cash outflows that would be absent in a frictionless market. The financial economics (cf., among others, Jensen and Meckling ${ }^{43}$ ) and actuarial literature (cf., among others, $\mathrm{Ng}$ and Varnell ${ }^{44}$ ) have detected a large number of frictions that could affect the value of insurance liabilities. Some important sources of frictional costs include costs of distress

\footnotetext{
${ }^{41}$ Santomero and Babbel (1997).

42 cf. Froot and O'connel (2008).

43 Jensen and Meckling (1976).

${ }^{44} \mathrm{Ng}$ and Varnell (2003).
} 
and bankruptcy, agency costs and frictional costs of raising capital in the market, tax asymmetries and other fiscal effects. ${ }^{45}$ For financial institutions, regulatory restrictions could also be relevant.

Frictional costs primarily affect the expected value of liability cash flows. In particular, they can increase the liability cash outflows in all or some scenarios. Conceptually, such cash outflows should be included in the cash flow estimate and not affect the risk margin. Actually, the scenarios may be based on a frictionless hypothesis, that is without directly considering some frictional costs, and hence the risk margin could also (improperly) consider the expected costs of the frictions (cf. Eq. (11)). If the frictional costs uniformly affect all scenarios and are not correlated to priced risk sources, only the effects on the expected frictional costs should be considered and the pure frictional cost approach in (11) could be assumed to hold.

Frictional costs usually depend directly on priced risks or only affect some scenarios and can therefore be indirectly related to priced risks. In these situations frictional costs affect not only the expected cash flows, but also the stricto sensu risk margin. For instance, this is the case for the cost of distress, that is all the incremental cash outflows relating to the worst scenarios. In this situation the frictional costs are higher with high liability cash outflows (worst scenarios) and lower with low liability cash outflows (best scenarios). This clearly increases the exposure of liabilities to priced risk and so increases the risk margin (cf. Eq. (12). In this case $r_{F C}<r_{f}$ ). The frictional costs that are negatively correlated to the cash outflows decrease the exposure of liabilities to priced risks and therefore contribute to a risk margin decrease such as agency costs which could have this characteristic $\left(r_{F C}>r_{f}\right)$. In the case of insurance liabilities an example of such a cost could be related to the fact that, in a very good scenario (low liability cash outflows), the antitrust authorities could choose to investigate if normal market conditions operate in that specific line of business.

\section{On the theoretical consistency of the Solvency II cost of capital approach}

It is now possible to discuss and to exemplify the three interpretations of the Solvency II risk margin estimation.

\section{The consistency of the indirect cost of capital approach}

Practitioners often suggest using the indirect cost of capital approach. Only insurance equity is traded in financial markets and therefore, only the cost of shareholder capital could be estimated on a market-consistent basis. Unfortunately, this approach seems impractical.

At least seven important issues should be considered beforehand.

First, the equity and the cost of capital observed in the financial markets are not consistent with regard to the equity and cost of capital reported in the balance sheet.

\footnotetext{
${ }^{45}$ The fiscal effects should always be considered carefully. Due to the fact that these effects are already adequately studied in the literature at hand (cf., for instance, Hitchcox et al., 2007) and also that this paper only deals with conceptual issues, the fiscal effects on the cost of capital estimation are left aside.
} 
The shareholders' market equity includes the franchise value, that is the value of the shareholders' net cash flows obtainable by the future business (cf. O'keeffe et al., ${ }^{46}$ Appendix B), that is not recorded in the balance sheet equity. It is possible to demonstrate $^{47}$ that the balance sheet cost of capital depends on, among others, the expected dynamics on franchise value. As a matter of fact, the cost of capital approach estimation should pass through a consistent estimation of the franchise value and its expected future dynamics, but there is no clear way to estimate the expected dynamics on franchise value without discretion.

Second, the estimated cost of balance sheet equity considers not only non-hedgeable risks but also the hedgeable risks. Consequently, the cost of shareholders' equity used in the risk margin computation must be set aside from the hedgeable risks. Yet again this issue is adequately analysed in the current literature. Ernst and Young, ${ }^{9}$ for example, observes that the lapse risk could be affected by interest rate risks and therefore poses a question as to whether it is possible to directly calibrate the cost of capital for non-hedgeable risk separately from the hedgeable risks using market rates of return on invested capital.

Third, the indirect approach leads to a fixed cost of capital that does not specifically refer to the different insurance lines of business or insurance contract portfolios. Clearly, each insurance portfolio could have a different systematic risk or different priced risk. Some empirical studies (cf. Cummins and Phillips ${ }^{48}$ ) reveal that differences are significant and therefore a single unitary cost of capital across lines of business and/or insurance portfolios seems unjustifiable.

The fourth issue relates to the cost of capital estimation. There are no univocal theoretical or empirical models in order to obtain a single cost of capital estimation. As pointed out by Nawalkha and Schwarz, ${ }^{49}$ the theoretical and empirical research of the factors which actually affect security expected return is ongoing. According to existing empirical studies on the insurance sector (cf. Derrig and Orr; ${ }^{50}$ Cummins and Phillips; ${ }^{48} \mathrm{Scotti}^{12}$ ) the estimated cost of shareholders' capital strongly depends on the methodology applied in the estimates.

The fifth issue relates to the possible segmentation between financial and insurance markets. The cost of capital is the rate of return, in addition to the risk-free rate that the insurance market participants require to exchange the insurance contract cash flows. In the indirect cost of capital approach, due to the absence of a sufficient active and relevant market for insurance contracts, the cost of capital estimation is based on insurance company equity, which, at least in theory, could be estimated by observing financial market prices. This estimate is the risk premium required by financial market participants. There is evidence that the financial market risk premium could be highly variable, since financial markets are particularly influenced by speculators and operators who have short term time horizons. On the other hand, the insurance market participants traditionally operate on a medium or long-term basis, so the

\footnotetext{
${ }^{46}$ O'keeffe et al. (2005).

${ }^{47}$ cf. Exley and Smith (2006).

48 Cummins and Phillips (2005).

${ }^{49}$ Nawalkha and Schwarz (2004).

${ }^{50}$ Derrig and Orr (2004).
} 


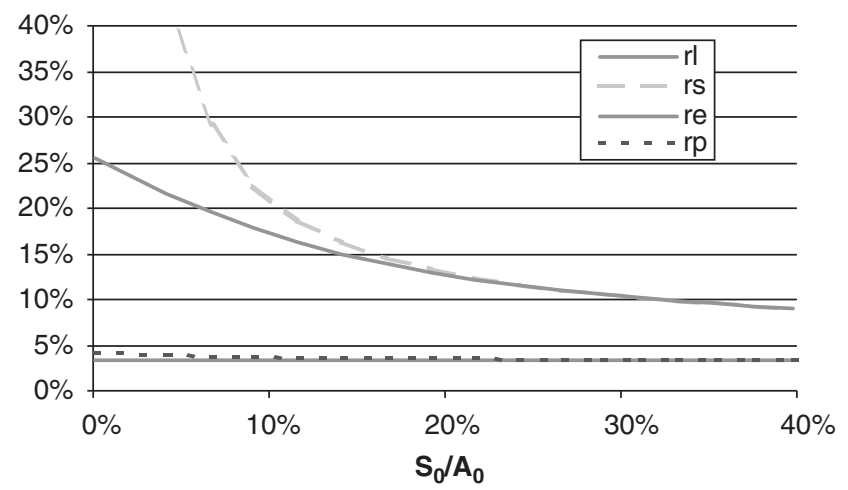

Figure 1. The expected rate of return on contractual liabilities $\left(r_{L}\right)$, insurance liabilities $\left(r_{P}\right)$, surplus $\left(r_{S}\right)$ and equity $\left(r_{E}\right)$ as a function of the ratio $S_{0} / A_{0}$.

$\boldsymbol{L}_{\mathbf{1}}$ is lognormally distributed, $r_{f}=5$ per cent, $E\left(\boldsymbol{L}_{\mathbf{1}}\right)=95, C V\left(\boldsymbol{L}_{\mathbf{1}}\right)=10$ per cent, $\left(r_{f}-r_{L}\right)=1.6016$ per cent, $A_{0}$ is variable.

market risk premium could be more stable and closer to its long-term level. Therefore, the use of financial market parameters in insurance contract valuation should be considered with prudence.

The sixth issue is specifically related to the Solvency II cost of capital approach. In the Solvency II framework, the cost of capital is not referred to a specific real insurance company but to a reference entity, a hypothetical insurance company with equity funds exactly equal to the SCR. On the one hand, there is no possibility to observe such a company on the market. On the other hand, due to the frictional costs, the cost of capital of a company that operates exactly at the SCR level is likely to be much higher than the one that should be used to correctly price the insurance portfolio.

The final and most critical point is that the indirect cost of capital approach (Eqs. [8] and [10]) is elusive. In a frictionless framework, the fulfilment or fair value of insurance contracts may be computed using the cost of shareholders' capital, however, it is in no way affected by the cost of shareholders' capital. More specifically, the fulfilment value of insurance contracts depends on expected cash flows, systematic risks on contractual obligations and market conditions (the market risk premium and the risk-free rate) but it is totally independent to the financial structure of the firm and the shareholders' cost of capital.

The idea that in frictionless markets the risk margin may be calculated, but does not depend on the shareholders' cost of capital, could seem odd, but it is simply a paraphrase of the famous Modigliani and Miller ${ }^{51}$ irrelevance theorem. In fact, if $\boldsymbol{L}_{\mathbf{1}}$ remains unaltered, any shareholders' net asset inflow (or outflow) perfectly reduces (or increases) the unitary shareholders' cost of capital in a way that the risk margin remains unchanged. In Figure 1 this critical point is graphically illustrated.

${ }^{51}$ Modigliani and Miller (1958). 
Figure 1 uses a classic Black and Scholes perfect market model with $\boldsymbol{L}_{\mathbf{1}}$ lognormally distributed to depict the adjusted discount rate on contractual obligations $\left(r_{L}\right)$, insurance liabilities $\left(r_{p}\right)$, surplus $\left(r_{s}\right)$ and equity $\left(r_{e}\right)$ as a function of the ratio between $S_{0}$ and $A_{O}$.

The characteristics of contractual obligations- $E\left(\boldsymbol{L}_{\mathbf{1}}\right)$, the expected value of contractual cash flows, is $95, C V\left(\boldsymbol{L}_{\mathbf{1}}\right)$, the coefficient of variation, is 10 per cent, $r_{L}$ the expected rate of return on contractual obligation is 3.398 per cent-remains unchanged throughout the figure and only cash to $A_{O}$ is added or subtracted. Clearly, the value of contractual obligations $\left(L_{0}=91.8776\right)$, the total risk margin $(R M=1.4014)$ and $r_{L}$ are not affected by the specific leverage of the firm. However, (cf. Eq. (6)), a reduction in the surplus increases the shareholders' risk and their expected rate of return. Conversely, an increase in the surplus decreases $r_{s}$. For example: if $A_{0}=100$, then $S_{0} / A_{0}=8.12$ per cent, and $r_{S}=23.1$ per cent; if $A_{0}=116.403$, then $S_{0} / A_{0}=21.07$ per cent and $r_{S}=11.0$ per cent and if $A_{0}=130$, then $S_{0} / A_{0}=29.32$ per cent, and $r_{S}=8.9$ per cent. In each case, the indirect calculated risk margin is the present value of the product between $\mathrm{S}_{0}$ and the spread $\left(\mathrm{r}_{\mathrm{S}}-\mathrm{r}_{\mathrm{f}}\right)$, is $1.4014 .^{52}$

If the shareholders' limited liability is considered, ${ }^{53}$ the default option gives protection to the shareholders and this reduces $r_{e}$ compared to $r_{s}$ and increases $r_{P}$ compared to $r_{L}$. In this case the fair value of insurance liabilities (the risk margin) increases (decreases) with the ratio $S_{0} / A_{0}$.

The frictionless model is also useful to illustrate how the risk margin is differently affected by diversifiable and systematic risks. If diversifiable and systematic risks are uncorrelated, then the volatility of contractual obligations is:

$$
\sigma^{2}=\beta_{L}^{2} \times \sigma_{m}^{2}+\sigma_{D}^{2}
$$

${ }^{52} R M=8.122 \times(23.1 \%-5 \%) / 1.05=24.525 \times(11.0 \%-5 \%) / 1.05=38.122 \times(8.9 \%-5 \%) / 1.05=1.401$

53 The classic Black and Scholes formula is applied to evaluate insurance equity and liabilities. More specifically:

$$
\begin{aligned}
& E_{0}=\frac{E^{p}\left(M A X\left[A_{1}-\boldsymbol{L}_{1} ; 0\right]\right)}{\left(1+r_{f}\right)}=A_{0} \times N\left(-d_{2}\right)-L_{0} \times N\left(-d_{1}\right) \\
& P_{0}=\frac{E^{p}\left(A_{1}-M A X\left[A_{1}-\boldsymbol{L}_{1} ; 0\right]\right)}{\left(1+r_{f}\right)}=L_{0} \times N\left(-d_{1}\right)+A_{0} \times N\left(d_{2}\right)
\end{aligned}
$$

where

$$
d_{1}=\frac{\ln \frac{L_{0}}{A_{0} \times\left(1+r_{f}\right)}+\ln \left(1+r_{f}\right)+0.5 \times \sigma^{2}}{\sigma}
$$

$d_{2}=d_{1}-\sigma, N($.$) is the standard normal cumulative density function, \sigma=\sigma\left(\ln \frac{\boldsymbol{L}_{1}}{L_{0}}\right)=\sqrt{\ln \left(1+C V\left(\boldsymbol{L}_{1}\right)^{2}\right)}$ is the volatility parameter and $E^{P}($.) indicates the expectation under the risk neutral probability function. In order to obtain the risk margin estimation in the fair value case it is necessary to calculate $r_{e}$ and, subsequently, $r_{p}$. The expected rate of return on equity is $r_{e}=\frac{E^{Q}\left(\boldsymbol{E}_{1}\right)}{E_{0}}-1$ and the expected shareholder payoff at the end of the period under the real world probability distribution Q is $E^{Q}\left(\boldsymbol{E}_{1}\right)=A_{1} \times N$ $\left(-d_{2}^{*}\right)-L_{0} \times\left(1+r_{L}\right) \times N\left(-d_{1}^{*}\right)$ where:

$\bar{d}_{2}^{*}=\mathrm{d}_{1}^{*}-\sigma$.

$$
d_{1}^{*}=\frac{\ln \frac{L_{0}}{A_{1}}+\ln \left(1+r_{L}\right)+0.5 \sigma^{2}}{\sigma}
$$




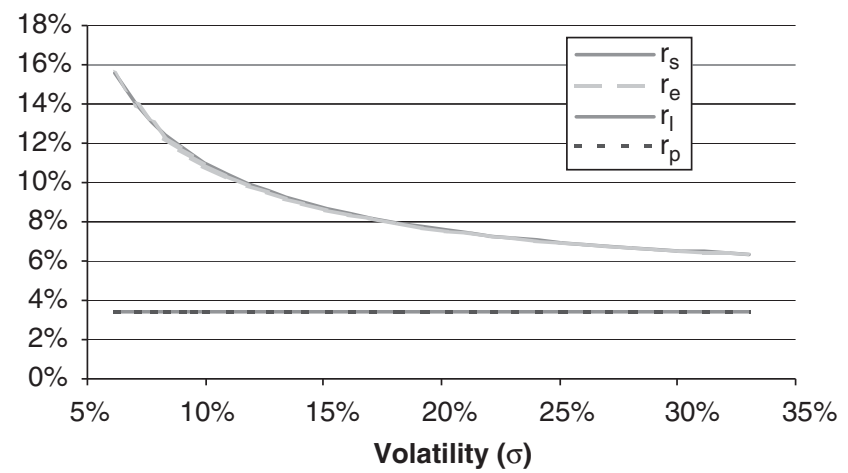

Figure 2. The expected rate of return on contractual liabilities $\left(r_{L}\right)$, insurance liabilities $\left(r_{P}\right)$, surplus $\left(r_{S}\right)$ and equity $\left(r_{E}\right)$ as a function of diversifiable contractual liability risk $\left(\sigma_{D}\right)$ with a constant default probability. $\boldsymbol{L}_{\mathbf{1}}$ is lognormally distributed, $r_{f}=5$ per cent, $E\left(\left(\boldsymbol{L}_{\mathbf{1}}\right)\right)=95$, and $\left(r_{f}-r_{L}\right)=1.6016$ per cent, $C V\left(\boldsymbol{L}_{\mathbf{1}}\right)$ is a function of $\sigma$ and $\sigma$ is computed using $\beta_{L}=-0.3074, \sigma_{m}=20$ per cent and $\sigma_{D}$ variable. $A_{0}$ is also variable, in order to maintain default probability at the 0.5 per cent level. In the $x$-axis the total volatility $(\sigma)$ is represented in order to maintain a better comparability with figure (4).

where $\beta_{L}$ is the contractual liability beta, $\sigma_{m}$ is the volatility on the market portfolio and $\sigma_{D}$ is the residual diversifiable volatility. As the base case assumes that $\beta_{L}=-0.3074, \sigma_{m}=20$ per cent and $\sigma_{D}=7.8551$ per cent, it leads to total volatility equal to 9.9751 per cent and to a coefficient of variation equal to 10 per cent.

If the risk margin is computed as in the Solvency II framework, that is as a product between the SCR and the cost of capital rate, a change in volatility should also affect the SCR. With a lognormal contractual liability distribution, the SCR could be analytically computed. If assets are invested in riskless securities, the amount of surplus that should be held at time 0 in order to maintain the default probability at $\alpha$ is:

$$
\operatorname{SCR}(\alpha)=\frac{\exp \left[\frac{N^{-1}(1-\alpha)-\mu}{\sigma}\right]}{\left(1+r_{f}\right)}-L_{0}
$$

where

$$
\mu=2 \ln \left[E\left(\boldsymbol{L}_{1}\right)\right]-0.5 \ln \left[E\left(\boldsymbol{L}_{1}\right)^{2}+\sigma\left(\boldsymbol{L}_{1}\right)^{2}\right]
$$

and $N^{-1}($.$) is the inverse of the standard normal cumulative density function.$

Figure 2 considers a situation in which $\sigma_{D}$ is variable, systematic risk remains unchanged and the effect of the change in volatility on default probability is neutralized, that is the assets $A_{0}$ are variable in order to guarantee that $S_{0}$ is equal to the $S C R(0.5$ per cent) obtained in Eq. (20). The fulfilment risk margin is once more unaffected and remains, as in the Figure 1 case, equal to 1.4014. Clearly, if a non priced risk is added, there cannot be any effect on the fulfilment value risk margin that exclusively depends on priced risks. The net assets (and equity ${ }^{54}$ ) unitary cost of capital varies strongly with the

${ }^{54}$ The difference between the fulfilment and fair value remains very low due to the fact that default probability is maintained constant at the 0.5 per cent level. This suggests that in the Solvency II framework the differences between the fulfilment value and fair value are not really significant. 


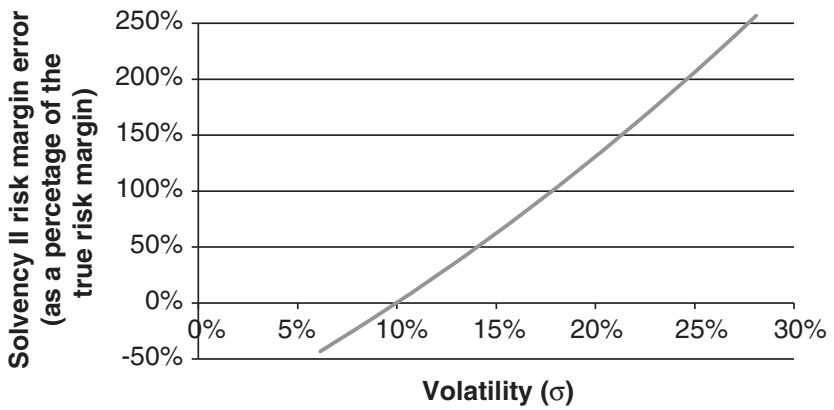

Figure 3. The risk margin error using the Solvency II formula as a function of diversifiable contractual liability risk $\left(\sigma_{D}\right)$ with a constant default probability.

The "true" risk margin is computed using Figure 2 parameters. The Solvency II risk margin is computed using a constant 6 per cent cost of capital $\left(r_{S}=11\right.$ per cent). The risk margin error ( $y$ axis) is computed as a percentage of the true risk margin. In the $x$-axis the total volatility $(\sigma)$ is represented in order to maintain a better comparability with figure (5).

volatility level and more precisely, decreases with an increase in volatility. When $\sigma_{D}$ is at zero, all volatility is systematic, $r_{s}$ is almost 16 per cent and the unitary cost of capital is almost 11 per cent. On the other hand, when $\sigma_{D}$ is high, the unitary cost of capital is less than 2 per cent. The logic behind this result has an intuitive explanation. The SCR increases with volatility. If the added volatility is diversifiable (and non-priced), this lowers the insurance leverage without increasing the priced liability risk. Therefore, the surplus (and equity) systematic risk and the unitary cost of capital both decrease as the volatility (and the SCR) increases. If the risk margin is calculated using a constant 6 per cent cost of capital rate, a sharp undervaluation of the true risk margin would be made in the case of low diversifiable volatility while a sharp overvaluation would be made in the case of high diversifiable volatility. Figure 3 depicts this error as a percentage of the true risk margin. The only situation in which the Solvency II formula correctly evaluates the risk margin is in the base case with total volatility equal to 9.9751 per cent and coefficient of variation equal to 10 per cent. In this case $r_{S}=11$ per cent and $r_{S}-r_{f}=6$ per cent.

In Figure 4 systematic risk varies, diversifiable risk remains unchanged and assets are adjusted in order to maintain a constant default probability. In this situation two opposite effects affect $r_{S}$. On the one hand, $r_{S}$ increases with liability systematic risk. On the other hand, this is offset by the increase in the SCR. Also in this situation, if the cost of capital rate is set constant and equal to the 6 per cent level (the base case) an error in the RM estimation is made (cf. Figure 5).

\section{The consistency of the direct cost of capital approach}

The Solvency II direct cost of capital approach is rational if the VaR or the SCR risk measures are proportional to the spread $\left(r_{f}-r_{L}\right)$, that is if (cf. Eq. (15)):

$$
R M\left(\boldsymbol{L}_{\boldsymbol{1}}\right)=\frac{k_{S} \times S C R\left(\boldsymbol{L}_{\boldsymbol{1}}\right)}{\left(1+r_{f}\right)}=\frac{k_{v} \times \operatorname{VaR} R_{99.5 \%}\left(\boldsymbol{L}_{\boldsymbol{1}}\right)}{\left(1+r_{f}\right)}
$$

with $k_{s}$ fixed (6 per cent according to QIS5). 


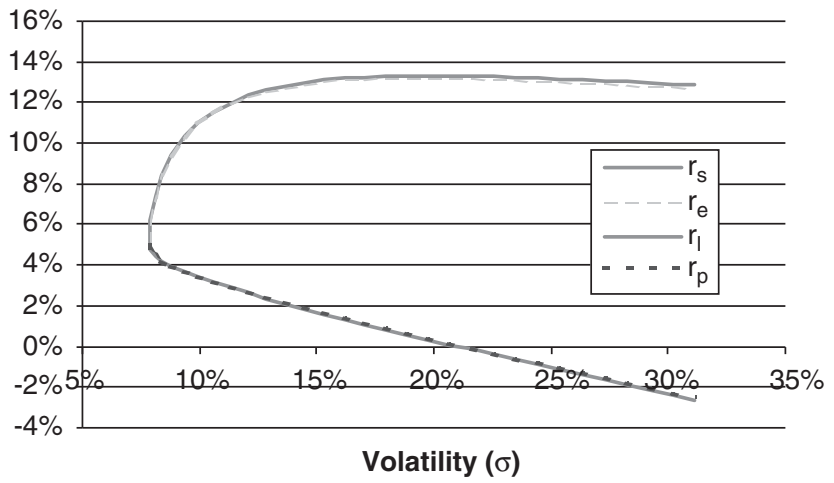

Figure 4. The expected rate of return on contractual liabilities $\left(r_{L}\right)$, insurance liabilities $\left(r_{P}\right)$, surplus $\left(r_{S}\right)$ and equity $\left(r_{E}\right)$ as a function of systematic contractual liability risk $\left(\beta_{L}\right)$ with a constant default probability. $\boldsymbol{L}_{\mathbf{1}}$ is $\operatorname{lognormally}$ distributed, $r_{f}=5$ per cent, $E\left(\boldsymbol{L}_{\mathbf{1}}\right)=95$, and $\left(r_{f}-r_{L}\right)=1.6016$ per cent, $C V\left(\boldsymbol{L}_{\mathbf{1}}\right)$ is a function of $\sigma$ and $\sigma$ is computed using $\sigma_{D}=7.8551$ per cent, $\sigma_{m}=20$ per cent and $\beta_{L}$ variable. $A_{0}$ is also variable, in order to maintain default probability at the 0.5 per cent level. In the X-axis the total volatility $(\sigma)$ is represented in order to maintain a better comparability with figure (2).

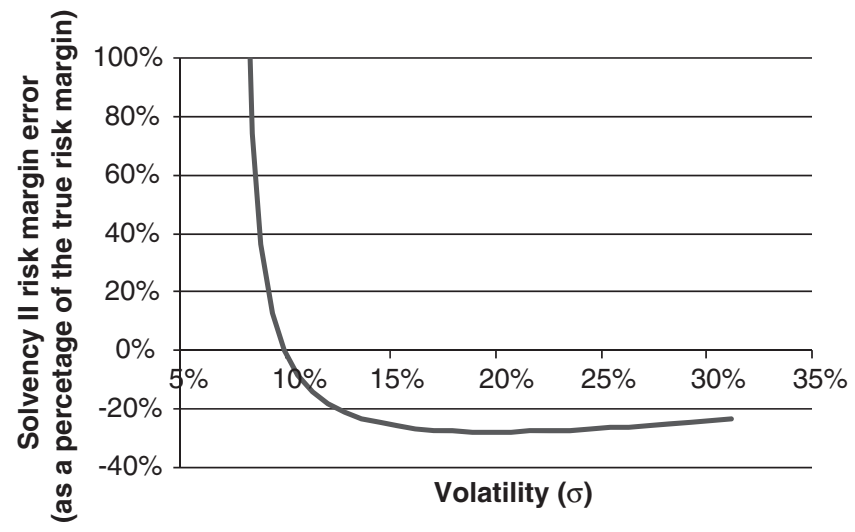

Figure 5. The risk margin error using the Solvency II formula as a function of systematic contractual liability risk $\left(\beta_{L}\right)$ with a constant default probability.

The "true" risk margin is computed using Figure 4 parameters. The Solvency II risk margin is computed using a constant 6 per cent cost of capital $\left(r_{S}=11\right.$ per cent). The risk margin error ( $y$-axis) is computed as a percentage of the true risk margin. In the $x$-axis the total volatility $(\sigma)$ is represented in order to maintain a better comparability with figures (3).

Unfortunately, also in a frictionless, complete, normally distributed and stationary world this is not the case, even if a simple formula that relates the risk margin to the SCR could be obtained. In this situation $k_{s}$ is not necessarily constant but only depends on the systematic liability risk and the market risk premium. More specifically, it is assumed that $\boldsymbol{L}_{\mathbf{1}}$ is normally distributed and traded in a frictionless 
and complete world and the traditional CAPM holds. In this situation (cf. Eq. (19)) the risk margin is:

$$
R M\left(\boldsymbol{L}_{\boldsymbol{l}}\right)=\frac{-\left(\bar{r}_{m}-r_{f}\right) \times L_{0} \times \beta_{L}}{\left(1+r_{f}\right)}
$$

In a normally distributed world, $\operatorname{VaR}_{99.5 \%}\left(\boldsymbol{L}_{\mathbf{1}}\right)=N^{-1}(0.995) \times \sigma^{\prime}\left(\boldsymbol{L}_{\mathbf{1}}\right)=2.576 \times$ $L_{0} \times \sigma^{\prime}{ }_{L}$, where $\sigma^{\prime}{ }_{L}=\sigma\left(\boldsymbol{L}_{\mathbf{1}}\right) / L_{0}$ is the contractual liability volatility. Therefore, with simple algebra, the unitary cost of capital on the VaR measure is:

$$
k_{v}=\frac{\left(r_{f}-r_{L}\right)}{\left(2.576 \times \sigma_{L}^{\prime}\right)}=-0.388 \times\left(\bar{r}_{m}-r_{f}\right) \times \frac{\beta_{L}}{\sigma_{L}^{\prime}}
$$

Clearly, to compute the risk margin, a risk measure based on $V a R$ is totally incompatible with a constant $k_{v}$. More specifically, $k_{v}$ strongly depends on the ratio $\beta / \sigma^{\prime}{ }_{L}$, that is the ratio between contractual liability systematic (priced) risk and total risk. Therefore, as in the indirect cost of capital interpretation, the unitary cost of capital strongly depends on the relative importance of diversifiable and systematic risk.

An additional key point should be considered. A constant $k_{v}$ is incompatible even within the same line of business but with a different portfolio size. More precisely, as in the lognormal case, if diversifiable and systematic risk are uncorrelated, then:

$$
\sigma_{L^{2}}^{\prime}=\beta_{L}^{2} \sigma_{m^{2}}^{\prime}+\sigma_{D^{2}}^{\prime}
$$

where $\sigma^{\prime}{ }_{D}$ is the residual (diversifiable) volatility. If $\sigma_{D}^{\prime}>0$, then $\sigma^{\prime}{ }_{L}>\beta_{L} \times \sigma_{m}$. In addition, $\beta_{L}$ is unaffected by the size of the insurance portfolio, while $\sigma_{D}{ }_{D}$ is a decreasing function of the insurance portfolio size. Therefore, $k_{v}$ is an increasing function of the portfolio size. This result has a very sound implication. If the relevant risk measure for risk margin calculation is based on $\mathrm{VaR}$, the unitary cost of capital should increase with the portfolio size or, if a fixed unitary cost of capital is used, the liabilities on large insurance portfolios are underevaluated and the liabilities on small insurance portfolios are overevaluated.

Figure 6 represents the unitary cost of capital on $\operatorname{SCR}\left(k_{s}\right)$ as an increasing function of the portfolio size.

Clearly, if a more realistic situation is considered (for instance, a positive skewed $\boldsymbol{L}_{\mathbf{1}}$ distribution and/or some frictional costs) the relationship between the VaR (or the SCR) and the risk margin becomes more obscure and the Solvency II cost of capital approach seems inappropriate even with a variable unitary cost of capital.

\section{The consistency of the frictional cost approach}

If the perfect market hypothesis is relaxed and frictions are introduced, the relevant frictions that affect the value of technical provisions have to be detected. In addition, the functional relationship between the friction and value should be estimated. In order to give consistency to the Solvency II cost of capital model, two different approaches are hereinafter discussed. 


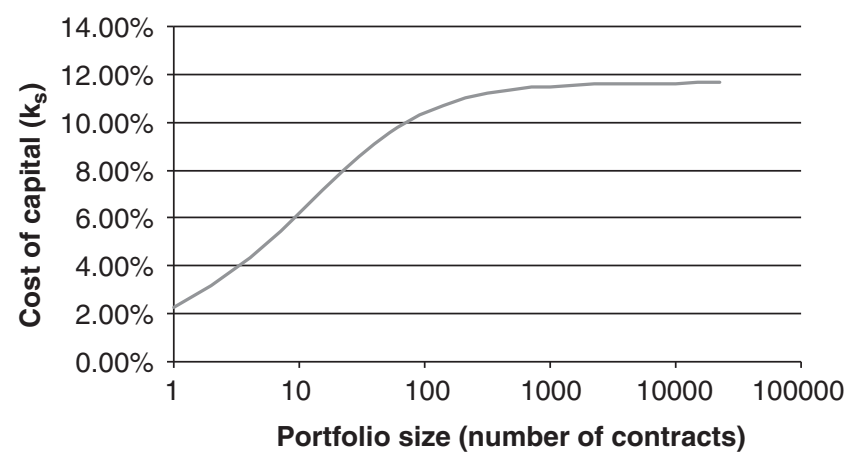

Figure 6. The unitary cost of capital on SCR $\left(k_{s}\right)$ as a function of portfolio size.

There are $n$ identical and independent contracts, each has a normally distributed $\boldsymbol{L}_{\mathbf{1}}, E\left(\boldsymbol{L}_{\mathbf{1}}\right)=95, \sigma_{D}=10$ per cent, $\beta_{L}=-0.1, r_{f}=5$ per cent and $\left(r_{m}-r_{f}\right)=6$ per cent. For $n=1, \sigma_{L}=10.20$ per cent, $r_{L}=4.40$ per cent, $L_{0}=91.00, R M=0.520, S C R=22.25$ and the ratio $S C R / L_{0}=24.45$ per cent. For $n=1000$ all the diversifiable risk is diversified and $\sigma_{L}=2.02$ per cent, $L_{0}=90996, R M=520, S C R=4000$ and the ratio between $S C R$ and $L_{0}$ is only 4.40 per cent.

The first is to assume that all systematic or priced risks are hedgeable and considered in the best estimate and that the only friction is a regulatory capital cost, that is a cost that does not exist without regulatory capital requirement. Using a simple incremental approach, this means that without SCR the insurance company shareholder capital would be unnecessary, insurance companies would be able to operate with zero shareholder capital and shareholders could alternatively invest their funds. In this zero-capital case, insurance companies would be able to operate, without difficulty, on the insurance markets and the shareholders' alternative investment could earn an additional 6 per cent return compared to the regulated case. This simple explanation might be considered plausible if such huge additional return, without any additional priced risk, could be effectively earned. How this is possible is completely unclear.

Another frictional cost candidate for the Solvency II cost of capital explanation could be related to the cost of distress. In the financial economics literature there is evidence $\left(\right.$ Branch $^{55}$ provides a general review, Staking and Babbel, ${ }^{56}$ provide some specific evidence on the insurance industry) that as firms' financial situations worsen, they suffer from growing costs that would not be present in a frictionless situation. The less complex functional form specification assumes that the cost of distress is proportional to the seriousness of the distress, that is the incremental cash outflows are:

$$
C \boldsymbol{D}_{1}=d \times M A X\left[\boldsymbol{L}_{1}-D ; 0\right]
$$

\footnotetext{
${ }^{55}$ Branch (2002).

${ }^{56}$ Staking and Babbel (1995).
} 
where $D$ is the level of cash outflow beyond which frictional costs start to emerge, and $d$ is the unitary cost as a percentage of the difference between $\boldsymbol{L}_{\mathbf{1}}-D$. In light of the frictional costs, if $E\left(\boldsymbol{L}_{\mathbf{1}}\right) \leqslant D \leqslant A_{1}$, contractual obligations and liabilities become respectively:

$$
\begin{gathered}
\boldsymbol{L}_{\boldsymbol{I}}^{\prime}=\boldsymbol{L}_{\boldsymbol{I}}+d \times M A X\left[\boldsymbol{L}_{1}-D ; 0\right]=\boldsymbol{L}_{1}+\boldsymbol{C D}_{\boldsymbol{l}} \\
\boldsymbol{P}_{\boldsymbol{I}}^{\prime}=\boldsymbol{L}_{1}-(1+d) \times M A X\left[\boldsymbol{L}_{1}-\frac{A_{1}+D \times d}{(1+d)} ; 0\right]+d \\
\times M A X\left[\boldsymbol{L}_{1}-D ; 0\right]=\boldsymbol{L}_{1}-\boldsymbol{C}_{1}^{\prime}+\boldsymbol{C} \boldsymbol{D}_{1}
\end{gathered}
$$

In the fair value measurement the cost of distress commences prior to the default threshold. It is simple to verify that the liability cash outflows in [24.] are equal to $\boldsymbol{L}_{\mathbf{1}}$ if $\boldsymbol{L}_{\mathbf{1}}<D$, to $\boldsymbol{A}_{\boldsymbol{1}}$ if the insurance companies are bankrupted ${ }^{57}$ and $\boldsymbol{L}_{\mathbf{1}}+d \times M A X$ $\left[\boldsymbol{L}_{\mathbf{1}}-D ; 0\right]$ in the distressful but solvent case.

The costs of distress in (23), as already discussed, are strictly related to priced risk sources due to the positive correlation between costs of distress and the contractual liability outflows. In addition, it is relatively simple to evaluate the liability fulfilment value, fair value and to estimate the risk margin, in a Black and Scholes framework. However, the priced risk case has already been analysed and hereinafter only the pure frictional cost approach is analysed (cf. Eq. (11)), that is the risk margin is equal to the present value of expected frictional costs. In this situation, if $\boldsymbol{L}_{\mathbf{1}}$ is lognormally distributed, the frictional cost risk margin is equal to:

where

$$
\begin{aligned}
R M & =E^{p} \frac{\left(\boldsymbol{C} \boldsymbol{D}_{1}\right)}{\left(1+r_{f}\right)}=E^{Q} \frac{\left(\boldsymbol{C} \boldsymbol{D}_{1}\right)}{\left(1+r_{f}\right)} \\
& =d \times\left[L_{0} \times N\left(d_{1}^{\prime}\right)-\frac{D \times N\left(d_{2}^{\prime}\right)}{\left(1+r_{f}\right)}\right]
\end{aligned}
$$

$$
\begin{gathered}
d_{1}^{\prime}=\frac{\ln \frac{L_{0}}{D}+\ln \left(1+r_{f}\right)+0.5 \times \sigma^{2}}{\sigma} \\
d_{2}^{\prime}=d_{1}^{\prime}-\sigma
\end{gathered}
$$

The risk margin is an increasing function of cash outflow volatility $(\sigma)$ and the $d$ parameter, while it is also a decreasing function of the critical point $D$.

\footnotetext{
57 The liability value is in the perspective of the shareholders. Therefore, in the bankruptcy case the shareholders receive nothing, irrespective of the bankruptcy costs that reduce the amounts received by the policy-holder. In the fulfilment value all bankruptcy costs are paid by the shareholders.
} 
In the situation depicted above, the Solvency II cost of capital approach could be explained rationally, if the frictional cost risk margin is proportional to the VaR or the SCR risk measure. Unfortunately, also with the pure frictional cost approach and with the simplest of specifications (23) this is not the case. The only risk measure that is perfectly proportional to expected frictional costs is the first order lower ${ }^{58}$ partial moment with target $D$, that is:

$$
R\left(\boldsymbol{L}_{1}\right)=E\left[\left(\boldsymbol{L}_{1}-D\right)^{+}\right]=E\left[M A X\left(\boldsymbol{L}_{1}-D ; 0\right)\right]
$$

What is more the Tail-VaR is related to this risk measure. More precisely, the Tail-VaR is defined as the distance between the expected loss by conditioning on the VaR scenario and the expected loss, that is:

$$
\begin{aligned}
\operatorname{TVaR}_{1-\alpha}\left(\boldsymbol{L}_{1}\right) & =\frac{E\left[\boldsymbol{L}_{1} \mid \boldsymbol{L}_{1} \geqslant \operatorname{VaR} R_{1-\alpha}\left(\boldsymbol{L}_{1}\right)\right]}{\alpha}-E\left(\boldsymbol{L}_{1}\right) \\
& =\operatorname{VaR}+\frac{E\left(M A X\left[\boldsymbol{L}_{1}-p_{1-\alpha}\left(\boldsymbol{L}_{1}\right) ; 0\right]\right)}{\alpha}
\end{aligned}
$$

If frictional costs are based on (23) with $D=p_{1-\alpha}\left(\boldsymbol{L}_{\mathbf{1}}\right)$, it is possible to compute that:

$$
R M=\frac{\left[\operatorname{TVaR}_{1-\alpha}\left(\boldsymbol{L}_{1}\right)-\operatorname{VaR}_{1-\alpha}\left(\boldsymbol{L}_{1}\right)\right] \times \alpha \times \mathrm{d}}{\left(1+r_{f}\right)}
$$

and therefore a risk measure proportional to the risk margin is:

$$
R\left(\boldsymbol{L}_{1}\right)=\operatorname{TVaR}\left(\boldsymbol{L}_{1}\right)-\operatorname{VaR}\left(\boldsymbol{L}_{1}\right)
$$

with $k_{T V}=\alpha \times d$

Intuitively, if the cost of distress occurs when the SCR is insufficient to guarantee liability settlements and the SCR is calculated through a VaR approach, the possible severity of the distress, that is the expected frictional cost, depends on the distance between TVaR and VaR. This distance depends on the volatility and asymmetry of $\boldsymbol{L}_{\mathbf{1}}$ distribution and in general on $\boldsymbol{L}_{\mathbf{1}}$ tail distribution, which might also be independent to the VaR. In this situation a numerical exercise does not seem to be strictly necessary in order to highlight the inadequacy of the SCR-VaR-based risk measure used for calculating the risk margin in this pure frictional cost approach.

${ }^{58}$ Eq. (27) expresses an upper partial moment. However, $\boldsymbol{L}_{\boldsymbol{1}}$ is a positive cash outflow random variable. If a negative cash flow random variable is considered, Eq. (27) reverses to a lower partial moment, that is a downside risk measure. 


\section{Conclusion}

This paper has addressed some conceptual issues on the risk margin estimation through the cost of capital approach and, more specifically, on the approach required by the Solvency II directive.

Even if there is a strong rationale for the cost of capital approach, the theoretical analysis developed in this paper has demonstrated that the Solvency II cost of capital specification does not seem to have one. Even if in a normally distributed and frictionless world, the risk margin is not proportional to the VaR or SCR risk measures and the unitary cost of capital depends on contractual liability systematic risk, which is the solely priced risk. The VaR or the SCR are inadequate to correctly price the risk margin simply because they are total risk measures which consider indifferently both priced and unpriced risks. If frictions were introduced, nonsystematic risks could also be priced and the expected cost of frictions could be considered in the risk margin. In this situation a single risk measure may not be sufficient to correctly calculate the risk margin. For example, if the expected cost of distress is considered in the risk margin computation, a downside risk measure based on Tail-VaR or lower partial moments is also likely to be needed in order to correctly gauge the risk margin. In this situation a more complete and coherent risk margin formula could be:

$$
R M=\frac{k_{\beta} \times R_{\beta}\left(\boldsymbol{L}_{\mathbf{1}}\right)+k_{T} \times R_{T}\left(\boldsymbol{L}_{\mathbf{1}}\right)}{\left(1+r_{f}\right)}
$$

where $R_{\beta}$ is the systematic risk measure, $k_{\beta}$ is the systematic unitary cost of capital, $R_{T}$ is a Tail-VaR or lower partial moment downside risk measure and $k_{T}$ is the downside risk unitary cost of capital. The risk margin Eq. (28) is coherent with financial economics literature (cf. Merton and Perold ${ }^{59}$ and Myers and Read ${ }^{60}$ ). For instance, Froot ${ }^{61}$ concludes that - due to frictions and asymmetries in insurance contract cash flow distributions - not two, but three risk measures affect the insurance firm value: systematic risk (quantity of market risk), total risk (firm-wide risk) and downside risk (quantity of asymmetry risk).

Finally, could the Solvency II cost of capital approach improve substantially with minor changes? The simplest way is to admit a unitary cost of capital differentiated across lines of business. The lines of business with systematic risk or with long tail risk are candidates for a higher unitary cost of capital. Conversely, with diversifiable risk or bell-shaped loss portfolio distributions a lower unitary cost of capital could be admitted. Furthermore, the unitary cost of capital should also depend on the size of the portfolio under evaluation. The smaller and less diversified the insurance portfolio is, the lesser the unitary cost of capital should be and vice versa.

In any case, insurance companies must pay particular attention when using the simplified Solvency II approach for capital allocation, product pricing or other

\footnotetext{
${ }^{59}$ Merton and Perold (1993).

${ }^{60}$ Myers and Read (2001).

${ }^{61}$ Froot (2007).
} 
managerial purposes. It could lead to the underestimation of the insurance liability value which would have relevant non-hedgeable systematic risks or long-tail risks. This might also result in a product mix that implies an exacerbation of the losses in systemic or firm-specific deep crisis situations.

\section{References}

Athanasoulis, S.G. and Shiller, R.J. (2000) 'The significance of the market portfolio', Review of Financial Studies 13(2): 301-329.

Babbel, D., Gold, J. and Merrill, C.L. (2002) 'Fair value of liabilities: The financial economics perspective', North American Actuarial Journal 6(1): 12-27.

Babbel, D. and Merrill, C.L. (1998) 'Economic valuation models for insurers', North American Actuarial Journal 2(3): 1-18.

Black, F. and Scholes, M. (1973) 'Pricing of options and corporate liabilities', Journal of Political Economy 81(3): 637-654.

Branch, B. (2002) 'The costs of bankruptcy: A review', International Review of Financial Analysis 11(1): 39-57.

Brealy, R. and Myers, S. (2003) Capital Investment and Valuation, New York, NY: McGrawHill.

Brennan, M. (1979) 'The pricing of contingent claims in discrete time models', Journal of Finance 34(1): 53-68.

Butsic, R.P. (1994) 'Solvency measurement for property-liability risk-based capital applications', Journal of Risk and Insurance 61(4): 656-690.

CEIOPS, Groupe Consultatif Actuariel Européen (2006) Solvency II: Risk Margin Comparison, Oxford, UK: CEIOPS, Groupe Consultatif Actuariel Européen.

CEIOPS (2008) 'QIS4 Background Document: Guidance on the Definition of the Reference Entity for the Calculation of the Cost of Capital', www.ceiops.eu, DOC 09/08, April 2008.

CEIOPS (2009) 'Final CEIOPS' Advice for Level 2 Implementing Measures on Solvency II: Technical Provisions-Article 86 (d). Calculation of the Risk Margin', www.ceiops.eu, DOC 36/09, October 2009.

Chief Financial Officer Forum (2009) 'Market Consistent Embedded Value Principles', from www .cfoforum.eu, October 2009.

Chief Risk Officer Forum (2006) A Market Cost of Capital Approach to Market Value Margins-Discussion Paper, The Chief Risk Officer Forum, 17 March 2006.

Chief Risk Officer Forum (2008) Market Value of Liabilities for Insurance Firms. Implementing Elements for Solvency II, The Chief Risk Officer Forum, July 2008.

Commission of the European Communities (2010) 'Technical Specifications for QIS 5', Draft, from http://ec .europa.eu/internal_market/insurance, July 2010.

Cummins, J.D. (1991) 'Statistical and financial models of insurance pricing and the insurance firm', Journal of Risk and Insurance 58(2): 261-302.

Cummins, J.D. and Phillips, R.D. (2005) 'Estimating the cost of equity capital for property-liability insurers', Journal of Risk and Insurance 72(3): 441-478.

Cummins, J.D., Phillips, R.D., Butsic, R.P. and Derrig, R.A. (2000) The risk premium project (RPP), phase I and II report, Casualty Actuarial Society, Committee on Theory of Risk, 30 June 2000.

Derrig, R.A. and Orr, E. (2004) 'Equity risk premium: Expectations great and small', Casualty Actuarial Society Forum Winter: 1-44.

Doff, R. (2008) 'A critical analysis of the Solvency II proposals', The Geneva Papers on Risk and InsuranceIssues and Practice 33(2): 193-206.

Doherty, N.A. and Garven, J.R. (1986) 'Price regulation in property-liability insurance: A contingent-claims approach', Journal of Finance 41(5): 1031-1050.

Duverne, D. and Le Douit, J. (2008) 'The IASB discussion paper on insurance: A CFO forum perspective', The Geneva Papers on Risk and Insurance - Issues and Practice 33(1): 41-53.

Duverne, D. and Le Douit, J. (2009) 'IFRS phase II and Solvency II: Key issues, current debates', The Geneva Papers on Risk and Insurance-Issues and Practice 34(1): 47-55. 
Ernst \& Young (2007) 'Market value margins for insurance liabilities in financial reporting and Solvency applications', Insurance and Actuarial Advisory Services, from http://www.gnaie.net/ research.htm, 1 November 2007.

Exley, C. J. and Smith, A.E. (2006) The Cost of Capital for Financial Firms, Presented to the Institute of Actuaries, Bell \& Bain, Glasgow.

Flamée, M. (2008) 'IFRS and solvency II: Global exposure and interaction-The work of the IAIS', The Geneva Papers on Risk and Insurance - Issues and Practice 33(1): 54-59.

Froot, K.A. (2007) 'Risk management, capital budgeting, and capital structure policy for insurers and reinsurers', Journal of Risk \& Insurance 74(2): 273-299.

Froot, K.A. and O'connel, P. (2008) 'On the price of intermediated risks: Theory and application to catastrophe reinsurance', Journal of Banking \& Finance 32: 69-85.

Hitchcox, A.N., Hinder, I.A., Kaufman, A.M., Maynard, T.J., Smith, A.D. and White, M.G. (2007) 'Assessment of target capital for general insurance firms', British Actuarial Journal 13(1): 81-168.

Holzmüller, I. (2009) 'The United States RBC standards, Solvency II and the Swiss Solvency test: A comparative assessment', The Geneva Papers on Risk and Insurance - Issues and Practice 34(1): 56-77.

International Accounting Standards Board (2007) 'Preliminary Views on Insurance Contracts. Discussion Paper, Part I and Part II', from www.ifrs.org, May 2007.

International Accounting Standards Board (2010) 'Exposure Draft 8/2010. Insurance Contracts', www.ifrs.org, July 2010.

Jensen, M. and Meckling, W. (1976) 'Theory of the firm: Managerial behaviour, agency costs and ownership structure', Journal of Financial Economics 3(4): 305-360.

Klumpes, P.J.M., O'Brien, C. and Reibel, A. (2009) 'International diversity in measuring the fair value of life insurance contracts', The Geneva Papers on Risk and Insurance - Issues and Practice 34(2): 197-227.

Margrabe, W. (1978) 'The value of an option to exchange one asset for another', Journal of Finance 33(1): 177-186.

Merton, R.C. (1973) 'An intertemporal capital asset pricing model', Econometrica 41(5): 867-887.

Merton, R.C. (1974) 'On the pricing of corporate debt: The risk structure of interest rates', Journal of Finance 29(2): 449-470.

Merton, R.C. and Perold, A. (1993) 'The theory of risk capital in financial firms', Journal of Applied Corporate Finance 6(3): 16-32.

Modigliani, F. and Miller, M.H. (1958) 'The cost of capital, corporation finance and the theory of investment', American Economic Review 48(3): 261-297.

Myers, S.C. and Read, J.A. (2001) 'Capital allocation for insurance companies', Journal of Risk and Insurance 68(4): 545-580.

Nawalkha, S. and Schwarz, C. (2004) 'The Progeny of CAPM', from SSRN: http://ssrn.com/ abstract $=966403$, June 2004.

Ng, H. and Varnell, E. (2003) Frictional Costs, London, UK: Staple Inn Actuarial Society.

O'Keeffe, P.J., Desai, A.J., Foroughi, K., Hibbett, G.J., Maxwell, A.F., Sharp, A.C., Taverner, N., Ward, M.B. and Willis, F.J.P. (2005) 'Current developments in embedded value reporting', British Actuarial Journal 11(3): 407-496.

Phillips, R.D., Cummins, J.D. and Allen, F. (1998) 'Financial pricing of insurance in the multiple-line insurance company', Journal of Risk and Insurance 65(4): 597-636.

Pollard, B. and Whitlock, P. (2006) 'Toward a standard for market consistent reporting', International Congress of Actuaries, from http://papers.ica2006.com.

Risk Margin Working Group (2007) Measurement of Liabilities for Insurance Contracts: Current Estimate and Risk Margins, Exposure Draft, International Actuarial Association, 23 February 2007.

Risk Margin Working Group (2008) Measurement of Liabilities for Insurance Contracts: Current Estimate and Risk Margins, Re-Exposure Draft, International Actuarial Association, 24 March 2008.

Santomero, A.M. and Babbel, D. (1997) 'Financial risk management by insurers: An analysis of the process', Journal of Risk and Insurance 64(2): 231-270.

Scotti, V. (2005) 'Insurers' cost of capital and economic value creation: Principles and practical implications', Sigma, Swiss Re publications, 3-2005.

Sherris, M. (2006) 'Solvency, capital allocation, and fair rate of return in insurance', Journal of Risk and Insurance 73(1): 71-96. 
Staking, K. and Babbel, D. (1995) 'The relation between capital structure, interest rate sensitivity, and market value in the property-liability insurance industry', Journal of Risk and Insurance 62(4): 690-718.

Swiss Federal Office of Private Insurance (2004) White Paper of the Swiss Solvency Test, November 2004.

\section{About the Author}

Alberto Floreani has a $\mathrm{PhD}$ in Financial Market Mathematics from the Università degli Studi, Brescia, Italy and is currently Associate Professor of Insurance Economics at Università Cattolica in Milan. His reaserch areas cover Risk Management, Insurance Economics and Accounting for insurance companies. 